\title{
Papers
}

\section{Women's reasons for not participating in follow up visits before starting short course antiretroviral prophylaxis for prevention of mother to child transmission of HIV: qualitative interview study}

\author{
Thomas M Painter, Kassamba L Diaby, Danielle M Matia, Lillian S Lin, Toussaint S Sibailly, Moise K Kouassi,
} Ehounou R Ekpini, Thierry H Roels, Stefan Z Wiktor

\begin{abstract}
Objective To find out why pregnant women who receive HIV-1 positive test results and are offered short course antiretroviral prophylaxis to prevent transmission of HIV from mother to child do not participate in necessary follow up visits before starting prophylaxis.

Design Qualitative interview study.

Setting A programme aiming to prevent transmission of HIV from mother to child at a public antenatal clinic in Abidjan, Côte d'Ivoire.

Participants Purposive sample of 27 women who had received HIV-1 positive test results and were invited to return for monthly follow up visits before starting prophylaxis with zidovudine at 36 weeks' gestation, but who had either refused or discontinued the visits. None of the women started prophylaxis. Results Most of the women explained their non-participation in follow up visits by referring to negative experiences that they had had while interacting with programme staff or to their views about the programme. Additional reasons concerned their disbelief of HIV positive test results and personal factors. Conclusions Difficulties experienced by women during their contacts with staff working on the prevention programme and negative views that they have about the programme can contribute to their non-participation in prophylaxis. Training and supervision of programme staff may increase the likelihood of positive interactions between staff and clients, thereby facilitating women's participation in preventing transmission of HIV from mother to child. Outreach and mobilisation in communities that are served by prevention programmes may complement these measures at programme level by contributing to increased social support for women's efforts to prevent transmission of HIV from mother to child.
\end{abstract}

\section{Introduction}

Interventions to prevent transmission of HIV from mother to child have become increasingly available in Africa, but many women do not participate. ${ }^{1-12}$ Refusal to be tested for HIV and non-receipt of HIV test results have been studied as barriers to participation, ${ }^{13-16}$ but no studies have examined why fewer than one third of pregnant women who receive HIV-1 positive test results eventually start taking antiretroviral prophylaxis. ${ }^{5-7} 9$ This problem affected a programme aiming to prevent transmission of HIV from mother to child in Abidjan, Côte d'Ivoire, where an estimated $12 \%$ of pregnant women are infected with HIV- $1 .{ }^{17}$
The programme has been implemented at a public antenatal clinic in the Koumassi commune by staff of Projet RETRO-CI, a public health partnership between Côte d'Ivoire's Ministry of Public Health and the US Centers for Disease Control and Prevention (CDC). ${ }^{4}$ At the time of our study, the programme included group counselling before HIV testing, conducted by trained social workers, followed by private sessions with social workers during which individual women accepted or refused HIV testing, and HIV testing; counselling two weeks after the test by trained social workers or programme doctors; and, for women whose test results were positive for HIV-1, monthly follow up visits with a programme midwife before starting free prophylaxis with a short course of zidovudine at 36 weeks' gestation; and zidovudine before and during labour. ${ }^{4}$ Programme staff informed women about the risks of HIV transmission through breast feeding but did not advise against it. During the programme's first 15 months of operations, from February 1998 to the end of May 1999, HIV testing was offered to 9657 women, of which $6982(72 \%)$ accepted the test. (Projet RETRO-CI conducted a randomised controlled clinical trial of the efficacy of short course zidovudine at the clinic from April 1996 to February $1998 .{ }^{4}$ ) Of the 884 women who tested positive for HIV-1, 395 $(45 \%)$ received their test results. Only $118(35 \%)$ of the 333 women who tested as positive for HIV, who received their test results, and who were invited to return for follow up visits during this period eventually started taking zidovudine. Of the 215 women who did not start taking zidovudine, 181 (84\%) had refused to return or discontinued follow up visits. Another 34 $(16 \%)$ were lost to follow up or removed from the programme because of early delivery, abortion, premature birth, death, or laboratory ineligibility; for example, unacceptably low haemoglobin levels (Projet RETRO-CI, unpublished data). ${ }^{4}$ At the request of Projet RETRO-CI, we studied women's nonparticipation in follow up visits before starting prophylaxis.

\section{Methods}

We conducted our qualitative, cross sectional study from October 1998 to the end of May 1999. We present interview data from women who had received test results that were positive for HIV-1 and had been invited by programme staff to return for monthly follow up visits, but who had either refused or discontinued the visits. None of them had started taking zidovudine. 


\section{Sample}

The women of interest to our study had no further contacts with programme staff, but they continued to see other staff at the clinic for consultations before and after giving birth, to have their babies vaccinated and weighed. Purposive recruitment was therefore possible, but it was first necessary to identify the women from among the hundreds who came to the clinic daily. A programme doctor (KLD) on our research team located them by visiting other clinic departments. In each instance, he explained that he was working with sociologists who wished to interview women concerning their views about the programme and to understand better why some participated while others did not. He asked to see their antenatal booklets and compared laboratory numbers that had been entered earlier by programme staff during counselling after being tested with a list of laboratory numbers for HIV-1 positive test results. Without mentioning their serostatus, he invited those women who had received HIV positive test results to speak with him in a quiet place near the waiting areas. He then verified that they knew their serostatus and had been invited to return for follow up visits, but had refused or discontinued the visits; he asked if they were interested in being interviewed and accompanied those who expressed an interest to meet an interviewer privately. One interviewer explained the study, another interviewer witnessed, and the women verbally agreed or refused to participate. The interviewers signed a consent form and offered the women a copy, the witness left the room, and the interview started. After the interviews, the women were offered $3000 \mathrm{CFA}$ (Communauté financière d'Afrique) francs (about $\$ 5.30$ at 1999 rate) as a gesture of appreciation for their time. We invited 40 women for interviews in this manner before completing our recruitment target of 30. All interviewed women were at least 18 years old.

\section{Data collection and analysis}

Female sociology students from the Université de Cocody (Abidjan) interviewed individual women in French or Dioula, asking open ended questions about their reasons for refusing or discontinuing follow up visits. The collected no identifying information; interviews lasted 82 minutes on average. All responses were written in French and were entered verbatim at Projet RETRO-CI. The electronic records were corrected at CDC in Atlanta on the basis of photocopies of the original interviews, and three were removed because of missing responses to questions about follow up visits. We used Analysis Software for Word-Based Records (AnSWR), version 3.1, revision 8 (CDC, Atlanta, Georgia) to code the 27 remaining records.

\section{Sociodemographic characteristics}

The median age of the women was 24. Eighteen had been born in Côte d'Ivoire; 14 were nationals of nearby West African countries. They had limited education (zero median years of completed schooling, range 0-9 years); 17 were non-literate in French. The median number of living children per woman was 1 (range 0-5); they reported 23 instances of miscarriages (3), stillbirths or infant deaths (13), or abortions (7). The median length of time since the women's latest HIV test was four months.

\section{Results}

Twenty four of the 27 women described their interactions with programme staff or their views about the programme when explaining their refusal or discontinuation of follow up visits; 14 did not believe their HIV positive test results; four described personal factors.

\section{Experiences at the programme}

Interactions with programme staff

Some women were dissatisfied with how HIV testing had been explained-for example, "If [the social worker] had talked about AIDS from the start, I would not have taken the test because I am afraid to know that I'll die from such a horrible disease" (interviewee 185, aged 22; refused follow up visits); others were unhappy with counselling after the test-for example: "The social worker told me I was negative and then she said that my blood was not clean. How can you be negative and have dirty blood? It is nonsense" (interviewee 183, aged 24; refused).

Some women were afraid of the staff-for example: "I did not want to continue the pregnancy [but she then changed her mind]. I was afraid to come back when I finally decided to keep the infant. I thought the doctors would chase me away; would yell at me" (interviewee 172, aged 20; refused); "I came for the appointment, but unfortunately I went to see a clinic midwife who had been seeing me. She told me that I did not have an appointment, so I did not know which midwife to see. I didn't know whom to ask, and I was afraid of being yelled at in front of the other pregnant women. So I went home, and I did not do anything else because I was discouraged" (interviewee 179, aged 36 (discontinued follow up visits)).

Four of the 13 women who had discontinued follow up visits could not find programme staff when they returned for their follow up appointments-for example: "I waited for more than one hour, but I did not find anyone. I continued my visits to [other clinic departments]. I did not have the courage to return" (interviewee 162, aged 20; discontinued); "I thought it was impossible to continue if I missed [sic] an appointment. I was afraid of the midwife's reaction. I was afraid to come back" (interviewee 166, aged 21; discontinued).

These responses indicate the importance of positive demeanour of the staff and clear explanations of the programme's procedures-for example, women who cannot complete follow up visits need to know that they will be welcomed, not scolded, for returning again. When women return, staff members must be available to meet them. Training for programme staff may be necessary in interaction skills, punctuality, etc. Additionally, periodic supervision and occasional interviews with women after their staff contacts may be useful for gauging the extent to which staff use their skills appropriately. The results of supervision and exit interviews need to be reviewed with staff promptly, and recurring issues need to be dealt with in subsequent training and supervision.

\section{Views about the programme}

Some of the women did not believe that prophylaxis was effective-for example: "We are told that the virus passes in the blood and my infant shares my blood. The contamination between me and my infant had already happened, so [there is] no hope of saving it. We have always been told that you can't cure AIDS, so the medications that I heard about are nothing but an illusion for me" (interviewee 186, aged 26; refused). The handling of blood specimens caused concerns: "The doctors can make mistakes with the blood during the test" (interviewee 171, aged 24 ; refused), as did fears that participation would lead to serostatus disclosure: "I wanted to think about it before deciding because I wanted to see how I could come back here without having someone I know learn about it. My husband might see me with the medicines, and he will want to know what they are for. That way he will find out about my [HIV positive test] result. Even the location bothers me, because everyone who comes to 
the clinic knows what goes on [at the programme]. As soon as a pregnant woman is seen coming here, it's known right away that she is seropositive" (interviewee 180, aged 24; refused). Costs also created barriers: "I was not able to complete any appointments, because of [not having] money for the ultrasound examination. If I don't have it, I won't be followed up by the midwife" (interviewee 175, aged 19; discontinued).

Programme staff need to ensure that their clients have up to date information on the interventions that are proposed to them. When, as is the case at the Abidjan facility, services for the prevention of transmission from mother to child are separate from other perinatal services, changes in the physical layout of service delivery may reduce the likelihood of unwanted visibility that can be associated with participating in interventions. Integrating prevention services for transmission from mother to child with other services for mothers and children may be helpful. Finally, programme policies could be modified to reduce or eliminate fees that impede participation.

\section{Disbelief of test results}

Fourteen of the women did not believe their HIV positive test results-for example: "I do not touch sharp objects that belong to other people; I have known only two men in my life, and I think they are not positive" (interviewee 159, aged 35; refused). "I was negative on my first test, and I have not had any changes in behaviour or partners" (interviewee 173, aged 30; refused). All three women who had discontinued the follow up visits for this reason added that they had had no intention of returning again-for example: "I'm sure that I am negative and my baby is fine; it's not sick. If I were positive like they say, I would not be in such good shape! I told the midwife that I would participate because I wanted to get away from her" (interviewee 165, aged 19; discontinued).

Programme staff need to explain that circumstances such as those described in the responses above, and which women may interpret as contributing to, or as being indicative of, a reduced risk or no risk of HIV infection, do not necessarily do either. Women must have accurate information about the circumstances of risk and effective prevention measures.

\section{Personal reasons}

These reasons included highly personalised reactions-for example: "I was ashamed of myself, to realise that I was infected by AIDS" (interviewee 186, aged 26; refused)-and descriptions of disruptions in women's lives: "I did not see the midwife because the social worker told me to come back another day. But I could not return because my house burned down and I had to move to Marcory [another neighbourhood]. This was a long distance for me, and I didn't have enough money to come here several times" (interviewee 170, aged 22; discontinued).

Although programmes cannot deal with unexpected events that affect women's lives, these examples show the importance of staff demeanour that is supportive of women's feelings and programme policies that are responsive to circumstances that may impede their participation-for example, the costs of transport to the programme could be covered.

\section{Discussion}

Factors associated with the functioning of a programme aiming to prevent transmission of HIV from mother to child created barriers to the participation of pregnant women who knew that they were HIV-1 positive in follow up visits that were necessary before starting zidovudine prophylaxis. For many of the women in the study, these barriers consisted of negative experiences that they had had or expected to have during their interactions with staff working at the programme.

\section{Strengths of the study}

No other studies in Africa have examined why pregnant women who have received HIV positive test results do not participate in antiretroviral prophylaxis after it has been offered to them. Furthermore, research on programme related barriers of any kind to participation in preventing transmission of HIV from mother to child is extremely limited. ${ }^{18} 19$ This contrasts with family planning, in which service delivery has been examined in order to increase service uptake. ${ }^{20-22}$ The organisational mechanisms-the policies, procedures, and the routine interactions between staff and clients-through which services for preventing transmission of HIV from mother to child are offered must be effective to increase the likelihood that women will participate.

\section{Outreach and mobilisation}

Many of the women were concerned about their problematic contacts with programme staff, but some of their responses-for example, with regard to fears about disclosure of their serostatus, their understandings, beliefs, and views about HIV risk, transmission of HIV from mother to child, its prevention, and about the programme itself-indicate that efforts may also be needed in the communities where women live. Involving women's partners in the prevention of transmission of HIV from mother to child is widely recognised to be desirable, but this rarely occurs. ${ }^{23-24}$ Outreach to couples in Zambia has increased participation by women's partners in HIV counselling and testing ${ }^{25}$; this approach may lend itself to adaptation by programmes that aim to prevent transmission of HIV from mother to child. In addition to media based approaches for disseminating prevention information, outreach focused on couples can provide women and their partners with opportunities outside antenatal settings-where men are rarely seen-to discuss and clarify their understanding of transmission of HIV from mother to child and options for prevention. Outreach to couples and community mobilisation may complement the measures at programme level that are suggested above by contributing to greater social support for women's prevention efforts, thereby increasing their sense of self efficacy and making it easier for them to protect their infants. ${ }^{23-28}$

\section{Generalisability of findings}

We used purposive recruitment to interview women who were difficult to reach; therefore our findings may not be generalisable to other women in similar circumstances. However, they provide insights concerning factors that can affect women's actions once they learn that they are HIV positive and that prophylaxis is available. Although this kind of study presents ethical as well as methodological challenges, our recruitment strategy aimed to protect women's confidentiality. Our team's programme doctor was as discreet as possible when contacting women about interviews. Both he and the interviewers emphasised that participation in interviews was voluntary and anonymous; all the women who were contacted could refuse either at the time of their initial contact or when they met interviewers. Most of the women spoke freely about their experiences; it is therefore possible that these structured conversations created opportunities for them to discuss topics that were difficult to discuss with other people, including, on a routine basis, programme staff. Focused dialogues of this kind offer the potential for increasing the capacity of programmes to prevent mother to child transmission of HIV to understand the circumstances of the women they serve better and to serve them more effectively. 


\section{What is already known about this topic}

Women's refusal of HIV testing and their non-receipt of HIV test results have been studied as barriers to the prevention of HIV transmission from mother to child in Africa

No studies have examined why pregnant women who receive HIV positive test results do not begin prophylaxis after it is offered to them

\section{What this study adds}

Difficulties experienced by women during their contacts with staff of a programme aiming to prevent transmission of HIV from mother to child, and negative views they have about the programme, can contribute to their non-participation in prophylaxis

Programme related barriers to women's participation need to be understood better and dealt with to facilitate the prevention of HIV transmission from mother to child

\section{Conclusion}

Barriers of the kind described in this paper may contribute to persistently low levels of participation in prophylaxis elsewhere in Africa by pregnant women after receipt of HIV-1 positive test results, but research on these factors has been limited. Greater efforts are needed by qualitative researchers and by management and staff of programmes for the prevention of transmission of HIV from mother to child, to clarify and address programme related barriers to protecting African infants from HIV infection.

We thank, in Abidjan, the women who were interviewed; our interviewers, Aubin Agnissan, Fatoumata Tirera, and Rosine Touré; and the following staff members of Projet RETRO-CI who helped: Kojo Aboagye, Marie Kofi Kouadjo Adjo, Agnès Adom, Aline Assoma, Adiza Bâ, Edith F. Boni-Ouattara, Kady Dao, Kady Dioumandé-Bamba, Mabel Enti, AnneMarie Kabran-Assavo, Yvonne Kamelan-Tano, Bénédicta Kouadio, Steven Kpaka, Nathalie Krou-Danho, Safiatou Lingani, Aboua Lucien, Bondo Monga, Delphine Chia N'guessan, Déborah N'Guessan-Yao, Jean Louis N'Jampo, Patricia Patindé, Albert Seri Sekou, Odette Tossou, Leo Weakland, Christiane Wondji Gozo. At the US Centers for Disease Control and Prevention, we thank Eliane Dogoré for help with coding; David Fluker, Eleanor McLellan, and Robert Strotman for software support; and Thomas Peterman, Marc Bulterys, Richard Jenkins, R J Simonds, and Monica Nolan for commenting on earlier versions of the manuscript. We also thank two $B M J$ reviewers for their useful comments and suggestions. This study was presented in part at the XIIth International Conference on AIDS and STDs in Africa, Ouagadougou, Burkina Faso, December 9-13, 2001 [abstract 10BT2-6].

Contributors: TMP, KLD, LSL, TSS, MKK, ERE, THR, and SZW designed the study. TMP, KLD, and TSS supervised data collection. MKK developed specialised strategies for data entry. TMP and DMM analysed interview responses. TMP wrote the paper with input from the coauthors and is the guarantor.

Funding: The research project was funded by the Centers for Disease Control and Prevention (CDC). All of the authors were employed directly or indirectly by the CDC during the design, collection and analysis of data, and write-up of findings.

Competing interests: None declared.

Ethical approval: Ethics committee of Côte d'Ivoire's Ministry of Public Health and the Institutional Review Board of the US Centers for Disease Control and Prevention.

1 Dabis F, Msellati P, Meda N, Welffens-Ekra C, You B, Manigart O, et al. 6-month efficacy, tolerance, and acceptability of a short regimen of oral zidovudine to reduce vertical transmission of HIV in breast-fed children in Côte d'Ivoire and Burkina Faso: a double-blind placebo-controlled multicentre trial. Lancet 1999;353:786-92.
2 Guay LA, Musoke P, Flemming T, Bagenda D, Allen M, Nakabiito C, et al. Intrapartum and neonatal single-dose nevirapine compared with zidovudine for prevention of mother-to-child transmission of HIV-1 in Kampala, Uganda: HIVNET 012 randomized trial. Lancet 1999;54:795-802.

3 Shaffer N, Chuachoowong R, Mock PA, Bhadrakom C, Siriwasin W, Young NL, et al. Short-course zidovudine for perinatal HIV-1 transmission in Bangkok, Thailand: a randomised controlled trial. Lancet 1999;353:773-80.

4 Wiktor SZ, Ekpini E, Karon JM, Nkengasong J, Maurice C, Severin ST, et al. Short-course oral zidovudine for prevention of mother-to-child transmission of HIV-1 in Abidjan, Côte d'Ivoire: a randomized trial. Lancet 1999;353:781-85.

5 Ekouevi DK, Rouet F, Becquet R, Inwoley A, Viho I, Tonwe-Gold B, et al. Immune status and uptake of antiretroviral interventions to prevent mother-to-child transmission tus and uptake of antiretroviral interventions to prevent moth
of HIV-1 in Africa. J Acquir Immune Defic Syndr 2004;36:755-7.

6 Malonza IM, Richardson BA, Kreiss JK, Bwayo JJ, Stewart GC. The effect of rapid HIV-1 testing on uptake of perinatal HIV-1 interventions: a randomized clinical trial. AIDS 2003;17:113-8.

7 Mouzin E, ed. MTCT News 2001; 2. New York: Unicef, 2001.

8 Msellati P, Hingst G, Kaba F, Viho I, Welffens-Ekra C, Dabis F. Operational issues in preventing mother-to-child transmission of HIV-1 in Abidjan, Côte d'Ivoire, 1998-99. Bull WHO 2001;79:641-47.

9 Sibailly TS, Ekpini ER, Kamelan-Tanoh A, Yavo D, Maurice C, Nkengasong J, et al. Impact of on-site HIV rapid testing with same-day post-test counseling on acceptance of short-course zidovudine for the prevention of mother-to-child transmission of HIV in Abidjan, Côte d'Ivoire. Abstract presented at the XIII International AIDS Conference, in Abidjan, Côte d'Ivoire. Abstract presented at the XIII Inter
Durban, South Africa, 9-15 July 2000. [Abstract WeOrC549.]

10 Songok EM, Fujiyama Y, Tukei PM, Vulule JM, Kiptoo MK, Adungo NS, et al. The use

Songok EM, Fujiyama Y, Tukei PM, Vulule JM, Kiptoo MK, Adungo NS, et al. The use
of short-course zidovudine to prevent perinatal transmission of human immunodeficiency virus in rural Kenya. Am J Trop Med Hygiene 2003;69:8-13.

11 Stringer EM, Sinkala M, Stringer JSA, Mzyece E, Makuka I, Goldenberg RL, et al. Prevention of mother-to-child transmission of HIV in Africa: successes and challenges in scaling-up a nevirapine-based program in Lusaka, Zambia. AIDS 2003;17:1377-82.

12 Temmerman M, Quaghebeur A, Mwanyumba F, Mandaliya K. Mother-to-child transmission in resource poor settings: how to improve coverage? AIDS 2003;17:123942.

13 Cartoux M, Meda N, Van de Perre P, Newell ML, de Vincenzi I, Dabis F. Acceptability of voluntary HIV testing by pregnant women in developing countries: an international voluntary HIV testing by preg
survey. AIDS 1998;12:2489-93.

14 Cartoux M, Msellati P, Meda N, Wellens-Ekra C, Mandelbrot L, Leroy V, et al. Attitude of pregnant women towards HIV testing in Abidjan, Côte d'Ivoire and Bobo-Dioulasso, Burkina Faso. DITRAME Study Group (ANRS 049 Clinical Trial), Diminution de la Transmission Mère-enfant du VIH, Agence Nationale de Recherches sur le SIDA. AIDS 1998;12:2337-44.

15 Kiarie J, Nduati R, Koigi K, Musia J, John G. HIV-1 testing in pregnancy: acceptability and correlates of return for test results. AIDS 2000;14:1468-70.

16 Ladner J, Leroy V, Msellati P, Nyirazliraje M, De Clercq A, Van de Perre P, et al. A cohort study of factors associated with failure to return for HIV post-test counseling in pregnant women: Kigali, Rwanda, 1992-1993. AIDS 1996;10:69-75.

17 Ezoua J, Sassan-Morokro M, Ekra A, Sidibé K, Maurice C, Nolan M, et al. Trends in HIV prevalence among pregnant women attending urban antenatal clinics in Côte d'Ivoire, prevalence among pregnant women attending urban antenatal clinics in Côte divoire,
1997-2000. Abstract presented at the XIIth International Conference on AIDS and STD in 1997-2000. Abstract presented at the XIIth International Conference on AIDS and STD
Africa. Ouagadougou, Burkina Faso, 9-13 December 2001. [Abstract 12PT5-416.]

18 Seidel G, Sewpaul V, Dano B. Experiences of breast-feeding and vulnerability among a group of HIV-positive women in Durban, South Africa. Health Policy Plann 2000;15:2433.

19 Mwai C, Rutenberg N, Kalibala S, Nduati R, Mbori ND, Nganda B et al. Provider time for women seeking MCH care in the Kenyan prevention of mother to child transmission (PMTCT) of HIV project: Baseline findings. Abstract presented at the Third Conference on Global Strategies for the Prevention of HIV Transmission from Mothers to Infants. Kampala, Uganda, 9-13 September 201. [Abstract 403.]

20 De Koninck, M. Le discours des femmes sur leur santé, un savoir essential pour lintervention. Recherches féministes 1997;10:97-112.

21 Prual A, Touré A, Huguet D, Laurent Y. The quality of risk factor screening during Prual A, Touré A, Huguet D, Laurent Y. The quality of risk factor
antenatal consultations in Niger. Health Policy Plann 2000;15:11-6.

22 Wilkinson D. Reducing perinatal mortality in developing countries. Health Policy Plann 1997;12:161-5.

23 Issiaka S, Cartoux M, Ky-Zerbo O, Tiendrebéogo S, Meda N, Dabis F, et al. Living with HIV: Women's experiences in Burkina Faso, West Africa. AIDS Care 2001;13:123-28.

24 Nebié Y, Meda N, Leroy V, Mandelbrot L, Yaro S, Sombié I, et al. Sexual and reproductive life of women informed of their HIV seropositivity: a prospective cohort study in Burkina Faso. J Acquir Immune Defic Syndr 2001;28:367-72.

25 Mckenna Sl, Muyinda GK, Roth D, Mwali M, Ng'andu N, Myrick A, et al. Rapid HIV testing and counseling for voluntary testing centers in Africa. AIDS 1997;11:S103-110.

26 Painter TM. Voluntary counseling and testing for couples: A high-leverage intervention for HIV/AIDS prevention in sub-Saharan Africa. Soc Sci Med 2001; for HiV/AII

27 Allen SA, Karita E, N'Gandu N, Tichacek A. The evolution of voluntary testing and counseling as an HIV prevention strategy. In: Gibney L, DiClemente RJ, Vermund SH,eds. Preventing HIV in developing countries: biomedical and behavioral approaches. New York: Plenum Press, 1999:87-108.

28 Farquhar C, Mbori Ngacha D, Bosire R, Nduati R, Kreiss J, John G. Prevalence and correlates of partner notification regarding HIV-1 in an antenatal setting in Nairobi, Kenya. Abstract presented at the XIII International AIDS Conference, Durban, South Africa, 9-15 July 2000. [Abstract TuOrC307.]

(Accepted 6July 2004)

Division of HIV/AIDS Prevention, National Center for HIV, STD and TB Prevention, Centers for Disease Control and Prevention, 1600 Clifton Road, NE, Mail stop E-37, Atlanta, Georgia 30333, USA

Thomas M Painter behavioral scientist

Lillian S Lin acting leader, statistics team

Stefan Z Wiktor chief, Surveillance and Infrastructure Development Branch, Global AIDS Program 
266th Pl SE, Sammamish, Washington 98075, USA

Danielle M Matia program officer

Projet RETRO-CI, US Embassy/CDC-HIV, 01 BP 1712 Abidjan 01, Côte d'Ivoire Kassamba L Diaby medical supervisor

Moïse K Kouassi manager, local area network

Department of HIV/AIDS (Prevention)-Room C-128, World Health Organization,

20 Avenue Appia, 1211 Geneva 27, Switzerland

Ehounou R Ekpini medical officer
Centers for Disease Control and Prevention, Global AIDS Program, Rwanda, US Embassy, BP 28, Kigali, Rwanda

Toussaint S Sibailly technical advisor

Global AIDS Program, BOTUSA Project, PO Box 90, Gaborone, Botswana Thierry H Roels associate director

Correspondence to: T M Painter tcp2@cdc.gov

bmj.com 2004;329:543 